\title{
Molecular detection of Anaplasma marginale in stable flies Stomoxys calcitrans (Diptera: Muscidae) feeding on a tick-free bovine herd
}

Carlos R. Bautista ${ }^{*}$

(D) 0000-0002-3359-8809

Tania Rodríguez ${ }^{\mathrm{a}}$

Carmen Rojas a

José J. Lira ${ }^{a}$

Jesús A. Álvarez ${ }^{\mathrm{a}}$

Diego Polanco ${ }^{\mathrm{a}}$

(D) 0000-0002-9239-5788

a Centro Nacional de Investigación Disciplinaria en Parasitologia Veterinaria,

Instituto Nacional de Investigaciones

Forestales, Agricolas y Pecuarias.

Carretera federal Cuernavaca-Cuautla

No. 8534, Colonia Progreso, C.P. 62550,

Jiutepec, Morelos.

*Corresponding author: Tel: (0155) 55-387 18700 Ext. 80420

Email address:

foto.dibujo@gmail.com

\section{Abstract}

Data on the implication of the stable fly (Stomoxys calcitrans, Diptera: Muscidae), in the transmission of Anaplasma marginale in tick-free cattle is scarce. Hence, the objective of this investigation was to detect the presence of DNA from A. marginale in stable flies caught near a bovine herd, which has been maintained free of ticks for 40 years, and occasionally presents some clinical cases of anaplasmosis. Twenty-four batches of $S$. calcitrans (15 flies each) were collected in the morning and in the afternoon twice a week (except for one catch in one week of September and one catch in one week of December) during 12 catching days in a period of four months. Their DNA was obtained and analysed by nested PCR (nPCR) to identify the presence of $A$. marginale DNA. Seven of the batches (29.16 \%) were positive for $A$. marginale, as detected by an $\mathrm{nPCR}$ that targets the $A$. marginale msp5 gene. Similarly, in two out of 12 catching days (16.66\%), those S. calcitrans batches collected in the morning and in the afternoon, were positive for $A$. marginale, while those $S$. calcitrans groups collected in three out of 12 catching days ( $25 \%$ ), were positive for the rickettsia. The obtained results suggest that $A$. marginale transmission is carried out mechanically by S. calcitrans, favouring the circulation and maintenance of the microorganism in this particular bovine herd.

Keywords: Anaplasma marginale, Stomoxys calcitrans, nested PCR.
Received: 2017-01-18 Accepted: $\quad 2017-12-07$

Published: $2018-01-26$

Additional information and declarations can be found on page 6

@ Copyright 2018 Carlos R. Bautista et al.

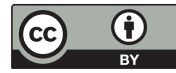

Distributed under Creative Commons CC-BY 4.0

\section{Cite this as:}

Bautista-Garfias CR, Rodríguez T, Rojas C, Lira JJ, Álvarez JA, Polanco D. Molecular detection of Anaplasma marginale in stable flies Stomoxys calcitrans (Diptera: Muscidae) feeding on a tick-free bovine herd. Veterinaria México OA. 2018;5(1). doi: 10.21753/ vmoa.5.1.436 


\section{Introduction}

The hemotropic rickettsia Anaplasma marginale causes bovine anaplasmosis and is transmitted biologically by ticks; however, different haematophagous Diptera (Tabanus sp., Haematobia irritans, Stomoxys calcitrans) can mechanically spread the rickettsia. ${ }^{1-3}$ In this context, anaplasmosis, together with bovine babesiosis, causes economic losses higher than 10 billion dollars worldwide. ${ }^{4}$ After transmission to bovines, the rickettsia multiplies in their erythrocytes. ${ }^{4}$ In the acute infection phase, the rickettsemia may reach $10^{9}$ infected erythrocytes (IE)/mL of blood. ${ }^{5}$ The main clinical signs of anaplasmosis are anaemia, weight loss, and abortion, and death is common. ${ }^{5}$ Recovered bovines become long-lasting carriers (clinically healthy) in which the rickettsia is very difficult to detect in blood smears examined with the optical microscope. 5,6

It is assumed that haematophagous flies mechanically participate in the transmission of $A$. marginale to the bovines, mainly during the acute phase of the infection in specific areas of the U.S.A. ${ }^{6}$ Furthermore, in some areas of Brazil ${ }^{7}$ and Costa Rica ${ }^{8}$ there is strong evidence that $S$. calcitrans actively participates in the mechanical transmission of $A$. marginale to cattle. In this connection, the minimal infectious dose (MID) of $A$. marginale-infected erythrocytes required for mechanical transmission is unknown. It has been suggested that it is in the range between the minimum of $1 \mathrm{IE}$ and $100 \mathrm{IE} .{ }^{6}$ Approximations of the amount of blood transported on stable fly mouthparts range from $0.029 \mathrm{~mL}$ to $0.4 \mathrm{~mL} .^{9,10}$ At an MID of $100 \mathrm{IE}$, rickettsemias between $2.5 \times 10^{8}$ (or $10^{8.4}$ ) IE/mL and $3.5 \times 10^{9}$ (or $\left.10^{9.5}\right) \mathrm{IE} / \mathrm{mL}$ would be necessary for a single fly to transport $1 \mathrm{MID}$. In fact, outbreaks of bovine anaplasmosis have been documented in some geographical areas where there are no ticks. ${ }^{11}$

S. calcitrans, is one of the biting flies implicated in the mechanical transmission of $A$. marginale among bovines, ${ }^{12}$ but there are not published reports that demonstrate this assumption. On this basis, the aim of this study was to detect DNA from A. marginale in S. calcitrans caught at 6 meters near a bovine herd, housed in pens with cement floors, which has been maintained free of ticks for 40 years, and occasionally experienced some cases of anaplasmosis.

\section{Materials and methods}

Sampling site

The study was carried out at an animal facility located at Progreso, Jiutepec, Morelos State, Mexico. It stands at $18^{\circ} 53^{\prime} \mathrm{N}, 99^{\circ} 10^{\prime} \mathrm{W}$, where the average warmest temperatures oscillate between $21.3^{\circ} \mathrm{C}$ (January) and $26.6^{\circ} \mathrm{C}$ (May), while the average coldest temperatures oscillate between $6.5^{\circ} \mathrm{C}$ (January) and $12.5^{\circ} \mathrm{C}$ (June). This facility houses a herd of 80 Aberdeen Angus cattle (65 females, 15 males) whose zootechnical function is meat production. Animals are housed in pens with concrete floors and they are fed with lucerne and a commercial supplement; and water is consumed ad libitum. This herd has sporadically experienced cases of anaplasmosis, and thus the bovines were examined every week to verify they have no ticks. There are a few farmers owning small numbers of cattle and horses in the vicinity. 


\section{Sampling of flies}

Groups of $15 \mathrm{~S}$. calcitrans were caught without touching them, when the flies were resting after a blood meal on the walls close ( 6 meters) to the cattle pens. Flies were caught by using a new sterile $50 \mathrm{~mL}$ plastic tube, containing $3 \mathrm{~mL}$ of sterile distilled water. A tube was slowly and carefully placed on a fly resting on the wall, and then the tube lid was screwed for trapping the fly. Afterwards, the tube was shaken to wet the fly wings and avoid it to scape when the tube was opened again to trap another fly. This procedure was repeated until 15 flies were captured in each tube.

Catches were done in the morning and in the afternoon, twice a week (except for one catch in one week of September and one catch in one week of December) for a total of 12 catching days during September, October, November and December 2015. Flies were identified as Stomoxys calcitrans according to morphological characteristics (seven to eight $\mathrm{mm}$ in length and look like house flies). ${ }^{13}$ They can be distinguished by belly marks in the form of chessboard and by the mouthparts for skin piercing (Figure 1A). ${ }^{13}$ Only those stable flies showing evidence by visual inspection of having taken a blood meal were collected (Figure 1A - photograph obtained by Carlos R. Bautista-). It is worth mentioning that no other haematophagous dipterans were identified at the time of the study. Immediately after capture, batches of 15 flies were placed in an Eppendorf vial $(2 \mathrm{~mL})$, and then the specimens were anesthetized through cold to manipulate them until processed. Whole ground fly batches were stored at $-70^{\circ} \mathrm{C}$ and prepared as described by Scoles et al. ${ }^{6}$ DNA extraction was carried out using the UltraClean ${ }^{\mathrm{TM}}$ BloodSpin ${ }^{\mathrm{TM}}$ DNA Isolation kit (MO BIO Laboratories Inc., Carlsbad, CA, U.S.A.) following the manufacturer's procedure.

Samples were tested for $A$. marginale DNA using a nested PCR (nPCR) that targets the amplification of a fragment from a single copy gene that encodes the outer major surface protein MSP5 from A. marginale. Reaction and amplification conditions were carried out as described by Torioni et al, ${ }_{1}^{13,14}$ using appropriate positive and negative controls. Sequences for the primers used were based on Torioni et $a l .{ }^{13}$ and the expected amplicons are described in Table 1.

Amplification conditions in a $\mathrm{C} 1000$ Touch $^{\text {TM }}$ Thermal cycler (BIO-RAD Laboratories, Inc., CA, U.S.A.) were: 35 cycles $95^{\circ} \mathrm{C}$ for 3 minutes, followed by 35 cycles at $95{ }^{\circ} \mathrm{C}$ for 30 seconds, 35 cycles at $65^{\circ} \mathrm{C}$ for 1 minute, and 35 cycles at $72{ }^{\circ} \mathrm{C}$ for 1 minute. A final extension step at $72{ }^{\circ} \mathrm{C}$ for 10 minutes was used, which was followed by 35 cycles at $4{ }^{\circ} \mathrm{C}$, at infinitum. The results of the PCR were analyzed in a $21 \%$ agarose gel stained with Ethidium bromide. Samples were considered positive when amplification of a fragment corresponding to the expected amplicon size was visualized under ultraviolet light (Figure 1B).

\section{Results and discussion}

Seven out of 24 S. calcitrans groups were positive for $A$. marginale as detected by a nested PCR, and an expected amplicon size of 466 bp (Figure 1B). This represented $29.16 \%$ of all the samples (Figure 2A). It was also observed that on two occasions, the $S$. calcitrans batches collected on the same day (morning and afternoon of October $22^{\text {nd }}$ and of November $4^{\text {th }}$ ), were positive for A. marginale $(16.66 \%)$, while those $S$. calcitrans batches collected in the afternoon of October $1^{\text {st }}$, morning 

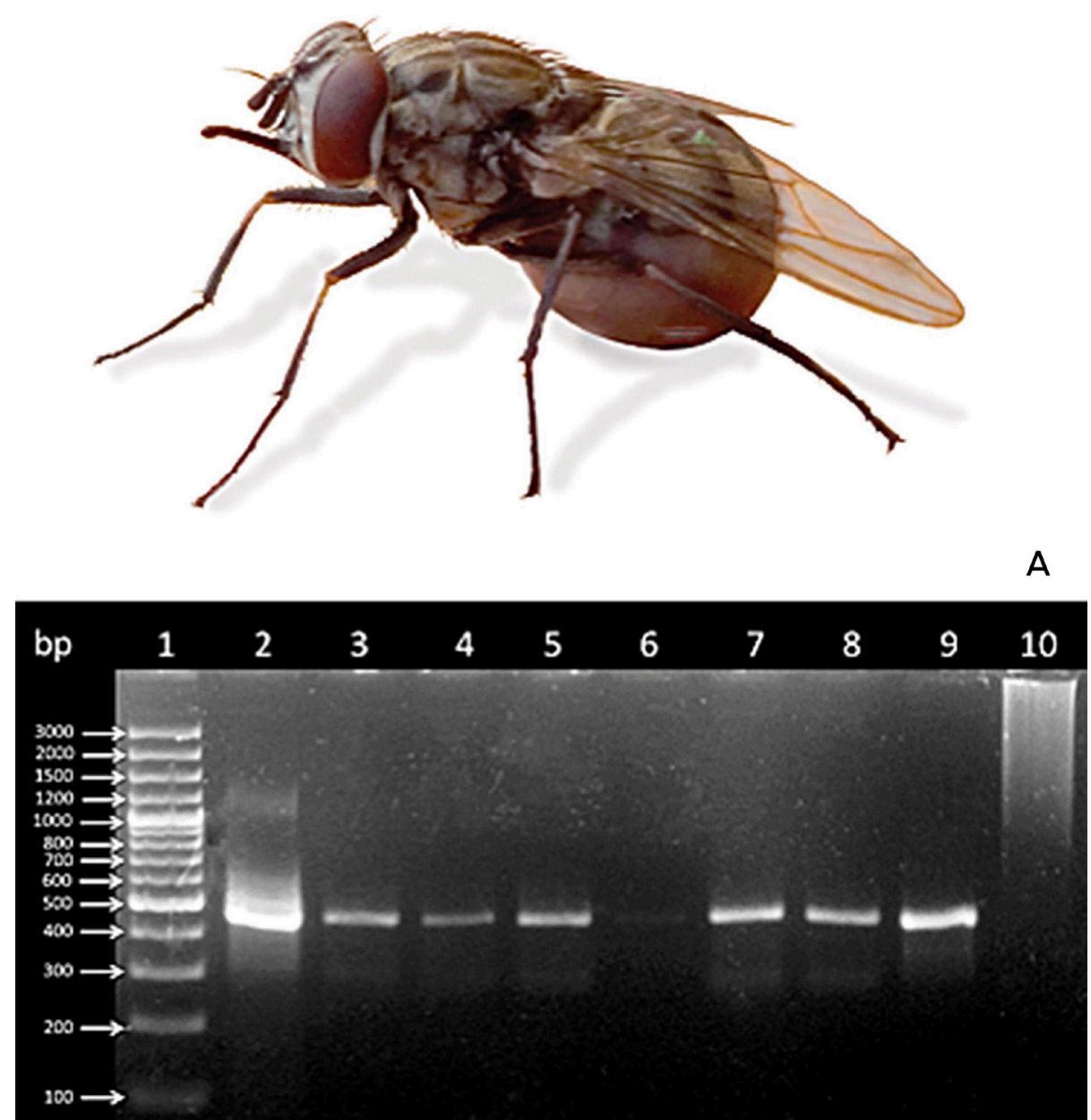

B

Figure 1. A. Example of a stable fly Stomoxys calcitrans caught in this study (photograph: Carlos R. Bautista). B. Agarose gel at $2 \%$ stained with Ethidium bromide, which shows the amplification products of msp5 of $A$. marginale by nested PCR. Lane 1: markers; lane 2, positive control; lanes 3 to 9, Stomoxys calcitrans samples; lane 10, negative control. (Sample in well 6 is positive, although the line is faint).

Table 1. Primers used for A. marginale DNA identification, based on the amplification of the Msp5 gene which codes for the major surface protein MSP5.

\begin{tabular}{|c|c|c|c|}
\hline Gene & Product & Primer sequence & Amplicon size (bp) \\
\hline Msp5 & Major surface protein MSP5 & F: 5' GCATACCCTCCCCCTCTTTC 3' & 548 \\
\hline & R: 5' TCCTCGCCTTCCCCCTCACA 3' & \\
\hline & F: 5' TACACGTCCCCTACCCACTTA 3' & 345 \\
\hline & R: 5' TCCTCGCCTTCCCCCTCACA 3' & \\
\hline
\end{tabular}



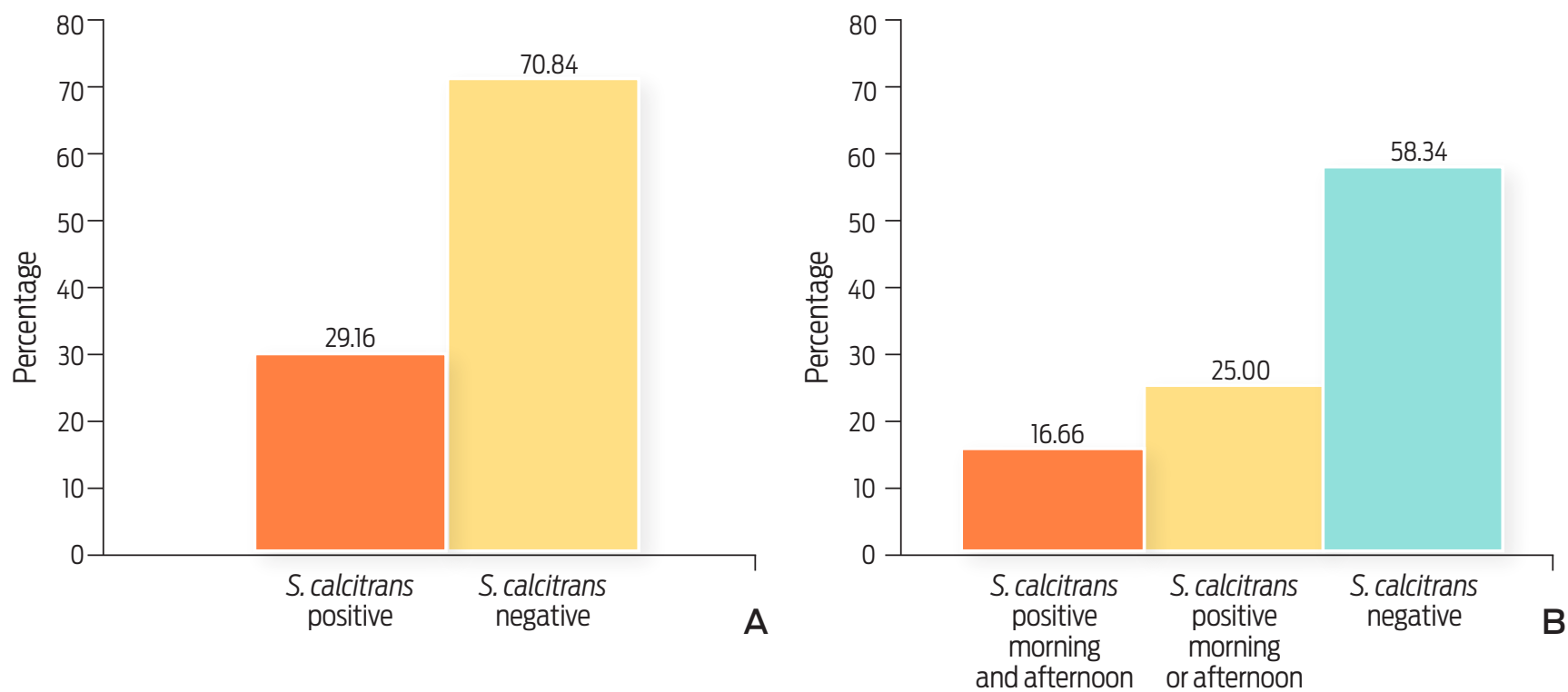

Figure 2. A. Percentage of $S$, calcitrans groups (15 flies / group) positive for $A$. marginale by nested PCR. Positive $(n=7)$, Negative $(n=17)$. B. Percentage of days of catching in which the S. calcitrans groups were positive for $A$. marginale. Samples positive in the morning and in the afternoon ( $n=2$ : one day-October $22^{\text {nd }}$ and one day-November $\left.4^{\text {th }}\right)$, samples positive in the morning or in the afternoon $\left(n=3\right.$ : afternoon of October $1^{\text {st }}$, morning of November 6 th , and afternoon of December $\left.1^{\text {st }}\right)$, Negative $(n=7)$.

of November $6^{\text {th }}$, and afternoon of December $1^{\text {st }}(25 \%)$ were positive for the rickettsia (Figure 2B).

The stable flies analyzed fed on tick-free animals of a bovine herd in an area (Morelos State, Mexico) considered as endemic of anaplasmosis. ${ }^{15}$ In an independent study carried out in bovines of the same herd (February 2017), it was observed that 15 (75\%) out of 20 animals were positive for anti-A. marginale antibodies by IFAT, (Pelaez-Flores A. 2017, personal communication). By comparison, in some dairy cattle herds seropositive for anti-Anaplasma marginale antibodies from Costa Rica, it has been observed that $S$. calcitrans is the only haematophagous parasite present, ${ }_{1}^{8}$ suggesting an active role in the mechanical transmission of A. marginale. Similarly, in recent and related studies, S. calcitrans has been associated with an outbreak of bovine anaplasmosis in Brazil. ${ }^{7}$

The results in the present study suggest that $S$. calcitrans mechanically transmitted A. marginale in bovines of a tick-free herd, and it is highly possible that contributed to the maintenance of the rickettsia in these animals. The recent finding of A. marginale DNA in a host other than cattle, like Myrmecophaga tridactyla (giant anteater), ${ }^{16}$ may expand the epidemiology of anaplasmosis, taking into account that $S$. calcitrans feeds from a variety of mammals, ${ }^{17,18}$ which may contribute to the mechanical transmission of $A$. marginale among different species. Under these circumstances, we hypothesize that $A$. marginale was mechanically introduced by biting flies into this bovine herd several years ago, and then the microorganism was mechanically transmitted by $S$. calcitrans (the most important haematophagous fly in this area) among the bovines. Thereafter, herd immunity ${ }^{19}$ was developed against $A$. marginale. However, some animals experience clinical anaplasmosis 
sporadically. In this context, a stable fly control program must be carried out the whole year in bovine industries in tropical and subtropical areas where anaplasmosis is endemic. It is advisable to take into account that in order to establish a control program it is necessary to generate information on the annual distribution of the ectoparasite in this particular area, because such information is not available.

\section{Conclusions}

Using a molecular test (nPCR) A. marginale DNA was detected in S. calcitrans caught next to a bovine herd, maintained free of ticks. This evidence indicates that the stable fly mechanically transmits this rickettsia, thereby circulating the pathogen among cattle in the absence of ticks. In further studies, it is suggested to test both flies (individually) and cattle at the same time for the presence of $A$. marginale DNA in order to better understand the epidemiology of anaplasmosis.

\section{Acknowledgements}

Authors thank DVM Alfredo Peláez for providing information in carring out this study.

\section{Conflicts of interest}

The authors declare that they have no conflict of interest with persons or institutions.

\section{Author contributions}

Carlos Ramón Bautista, Carmen Martínez and Jesús Antonio Álvarez designed the study, analyzed the data and wrote and revised the manuscript. Tania Rodríguez, José Lira and Diego Polanco collected the samples and carried out the assays.

\section{References}

1. Ewing SA. Transmission of Anaplasma marginale by arthropods. In: Hidalgo and Jones WE [eds.]. Proceedings of the seventh national anaplasmosis conference, Starkville, MS. Mississippi State University, Mississippi State. 1981; pp.425-434.

2. Potgieter FT, Sutherland B, Biggs HC. Attempts to transmit Anaplasma marginale with Hippobosca rufipes and Stomoxys calcitrans. Onderstepoort J Vet Res. 1981; 48:119-122.

3. Hawkins J.A, Love JN, Hidalgo RJ. Mechanical transmission of anaplasmosis by tabanids (Diptera:Tabanidae). Am J Vet Res. 1982; 43:732-734.

4. Lew-Tabor $A E$, Rodriguez Valle M. A review of reverse vaccinology approaches for the development of vaccines against ticks and tick borne diseases. Ticks Tick Borne Dis. 2016;7: 573-585.

5. French DM, McElwain TF, McGuire TC, Palmer GH. Expression of Anaplasma marginale major surface protein 2 variants during persistent cyclic rickettsemia. Infect Immun. 1998; 66: 200-1207.

6. Scoles GA, Broce AB, Lysyk TJ, Palmer GH. Relative efficiency of biological transmission of Anaplasma marginale (Rickettsiales: Anaplasmataceae) by Dermacentor andersoni (Acari:Ixodidae) compared with mechanical transmission by Stomoxys calcitrans (Diptera: Muscidae). J Med Entomol. 2005; 42: 668-675. 
7. Machado ZR, Barbosa da Silva J, André MR, Goncalves RL, Matos CA, Obregón D. Outbreak of anaplasmosis associated with the presence of different Anaplasma marginale strains in dairy cattle in the states of Sao Paulo and Goias, Brazil. Braz J Vet Parasitol Jaboticabal. 2015; 24:438-446.

8. Oliveira JB, Montoya J, Romero JJ, Urbina A, Soto-Barrientos N, Melo ESP et al. Epidemiology of bovine anaplasmosis in dairy herds from Costa Rica. Vet. Parasitol. $2011 ; 177: 359-365$.

9. Weber AF, Moon RD, Sorensen DK, Bates DW, Meiske JC, Brown CA, et al. Evaluation of the stable fly (Stomoxys calcitrans) as a vector of enzootic bovine leukosis. Am J Vet Res. 1988; 49:1543-1549.

10. Kloft WJ. Radioisotopes in vector research, pp. 41-66. In K. F. Harris [ed.], Advances in disease vector research. Springer, New York.1992.

11. Coronado, A. ¿Es Boophilus microplus el principal vector de Anaplasma marginale? Rev Cient FC-LUZ. 2001; $11: 408-411$.

12. Baldacchino F, Muenworn V, Desquesnes M, Desoli F, Charoenviriyaphap T, Duvallet $\mathrm{G}$. Transmission of pathogens by Stomoxys flies (Diptera, Muscidae): a review. Parasite. 2013;20:26.doi:10.1051/parasite/2013026.

13. Bautista Garfias CR. Entomología veterinaria esencial. Segunda edición. 2016. CENID-PAVET, INIFAP, Jiutepec, Morelos, México.

14. Torioni S, Knowles DP, McGuire TC, Palmer GH, Suarez CE, McElwain TF. Detection of cattle naturally infected with Anaplasma marginale in a region of endemicity by nested PCR and a competitive Enzyme-Linked Immunosorbent Assay using recombinant major surface protein 5. J Clin Microbiol. 1998; 36:777-782.

15. Rodríguez SD, García Ortiz MA, Jiménez Ocampo R, Vega y Murguía CA. Molecular epidemiology of bovine anaplasmosis with particular focus in Mexico. Infect Gen Evol.2009; 9:1092-1101.

16. Guillemi EC, de la Fourniere S, Orozco M, Peña Martínez, J, Correa E., Fernández J. et al. Molecular identification of Anaplasma marginale in two autochthonous south American wild species revealed an identical new genotype and its phylogenetic relationship with those of bovines. Parasites \& Vectors.2016; 9:305 DOI 10.11186/s13071-016-1555-9.

17. Zumpt F. The Stomoxyine biting flies of the world. Gustav Fischer Verlag. Stuttgart. 1973; pp. 137-152.

18. Pitzer JB, Kaufman PE, Tenbroeck SH, Maruniak JE. Host blood meal identification by multiplex polymerase chain reaction for dispersal evidence of stable flies (Diptera:Muscidae) between livestock facilities. J Med Entomol. 2011; 48:53-60.

19. Kocan KM, de la Fuente J, Guglielmone AA, Meléndez RD. Antigens and alternatives for control Anaplasma marginale infection in cattle. Clin Microbiol Revs. 2003; 16:698-712. 